\title{
Adrenocortical and behavioral reactions by differentially raised rhesus monkeys*
}

\author{
GENE P. SACKETT \\ Regional Primate Research Center and Department of Psychology, University of Washington, Seattle, Washington 98195 \\ and \\ ROBERT E. BOWMAN, JEROME S. MEYER, RICHARD L. TRIPP, and SHARON S. GRADY
Regional Primate Research Center, University of Wisconsin, Madison, Wisconsin 93706
}

\begin{abstract}
Monkeys reared in social isolation or with an agemate were tested at 19 months for cortisol responses following (1) ACTH injection and (2) initial experience in a novel playroom. Isolates had higher basal cortisol, but did not differ from peer-raised monkeys in absolute cortisol rise induced by ACTH or by the playroom experience. However, isolates did show more fear-disturbance-emotional behavior than did peers. The data suggest that basal cortisol level may be a meaningful correlate of behavioral differences produced by differential rearing experiences in monkeys, but cortisol rises induced by novel and complex stimulation are not correlated with these behavioral effects.
\end{abstract}

Stimulus deprivation or relatively low stimulus input levels in infancy produce anomalous postrearing behavior in a variety of mammalian species. Rats not reared with experiences such as handling, temperature changes, shock, or transportation to a new location show elevated defecation, depressed exploration, and very high or very low motor activity (Denenberg, 1967; Levine, Haltmeyer, Karas, \& Denenberg, 1967). Dogs raised in social isolation are hyperactive, disoriented, and fail to respond appropriately to painful stimulation (Fox, 1968; Melzack \& Scott, 1957; Scott, 1962). Rhesus monkey social isolates are hypoactive, nonexploratory, and engage in high levels of self-clutching, withdrawal, or repetitive stereotyped responses (Harlow, Dodsworth, \& Harlow, 1965: Sackett, 1968). A physiological correlate of varied rearing input identified for rats and mice is level of adrenal cortex hormone secretion (Hess, Denenberg, Zarrow, \& Pfeifer, 1969; Levine, 1962). Compared with stressed controls, rats and mice that are not stressed in infancy show greater increases in corticosterone output following experiences such as exposure to novelty, cold, or avoidance learning. In rhesus monkeys, a variety of stressful conditions such as chair restraint, electric shock, and subjection to difficult learning tasks have produced cortisol changes indicative of increased adrenal activity (Mason, 1968).

The purpose of this study was to assess adrenocortical responses and behavior under stressful conditions in monkeys who were reared under social restriction or social access conditions. It was expected that isolates

*This research was supported by USPHS Grant RR-0167 from the National Institutes of Health to the University of Wisconsin Regional Primate Research Center. We wish to acknowledge the efforts of Robert Graf in performing the blood steroid analyses. Reprint requests should be sent to Gene Sackett, University of Washington, Primate Research Center, Seattle, Washington 98195. would have higher basal cortisol levels than controls, under the assumption that isolation rearing is a chronic stress situation and that induction of both physiological stress by ACTH injection and environmental stress by subjection to a novel social environment would produce greater adrenal activity in isolate than in socially raised monkeys.

\section{METHOD}

\section{Subjects and Rearing Conditions}

The laboratory-born male Ss (Macaca mulatta) were raised from birth through 9 months either together in pairs $(N=4)$ or individually $(\mathrm{N}=4)$. One pair lived in a wire mesh cage where they could see other animals and humans; the other pair lived in a visually enclosed sound-attenuating chamber. One individually raised animal lived in a mesh cage, and the other three lived in total isolation sound chambers. All four isolates showed the isolation syndrome signs typical for rhesus monkeys (Sackett, 1968), while the paired monkeys did not show these signs.

From Months 9 to 18, all Ss were housed in back-to-back cages, from which one other monkey could be seen through a Plexiglas door in a wall common to each pair of cages. No monkeys other than the one housed in the adjacent cage could be seen. For $30 \mathrm{~min}$ each day, the Plexiglas door was opened, allowing physical interaction. Pairs were changed every 4 days, so all $\mathrm{Ss}$ were paired together in each 2-month period. At 3-month intervals, the Ss were also tested for social preferences and for instrumental learning in the self-selection circus apparatus (Sackett, 1970). Thus, through Month 18, the sole experiences of these monkeys were in their $79 \times 110 \times 110 \mathrm{~cm}$ rearing and postrearing cages and in the $90 \times 120 \times 140 \mathrm{~cm}$ compartments of the self-selection circus.

\section{Procedure}

The present study commenced when the Ss were 19 months old. Phase I involved an ACTH test. designed to estimate the maximum cortisol response of each S's adrenal system (Mason, 1968). In infant through adult rhesus monkeys, increasing doses of ACTH from 2 to 4,8 , and $16 \mu / \mathrm{kg}$ produced no further increases in circulating cortisol (Bowman \& Wolf, 1969), indicating that all doses in this range were maximally 


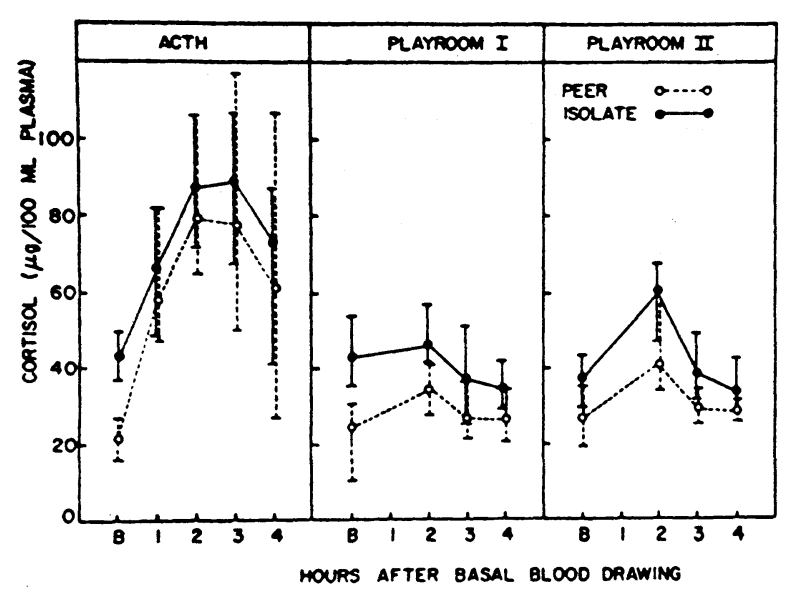

Fig. 1. Absolute plasma cortisol values for basal and poststress blood samples on ACTH and playroom test days. Bars indicate standard error of the mean.

stimulating. In our procedure, the monkey was caught and removed from his home cage between 1100 and $1200 \mathrm{~h}$, and $1 \mathrm{ml}$ of blood was withdrawn from the saphenous vein. This was immediately followed by intramuscular injection of $8 \mathrm{IU} / \mathrm{kg}$ ACTH (Cortrophin Gel, Organon). Blood was drawn every hour thereafter for $4 \mathrm{~h}$, with the monkey left in his home cage between drawings. The first blood sample yielded basal (unstimulated) plasma cortisol measures. The four subsequent samples yielded a time estimation of maximal adrenal responsiveness to the ACTH injection plus capture stress. All plasma cortisol analyses were done in duplicate, using a protein-binding technique described by Bowman and DeLuna (1968), demonstrated to be specific for cortisol in monkey plasma.

Phase II consisted of two playroom tests, the first given on the day following the ACTH test. Between 1100 and $1200 \mathrm{~h}, 1 \mathrm{ml}$ of blood was drawn as a basal sample. After all blood was collected (about $20 \mathrm{~min}$ ), all eight Ss were put together in a $2.5 \times 2.5 \times$ $2.1 \mathrm{~m}$ playroom containing shelves, toys, and climbing objects. None of the Ss had been in this environment before or in groups larger than two. Thus, this novel, complex, large playroom environment was assumed to be highly arousing and stressful. The playroom test lasted $1 \mathrm{~h}$. Two Os recorded the duration of a set of behavioral categories, scoring each $S$ for two 5 -min periods, once during the first and once during the second 30 min. After the test, Ss were captured, blood was drawn approximately $2 \mathrm{~h}$ after the initial basal sample, and the monkey was returned to his home cage. Blood was drawn again at Hours 3 and 4 after the basal sample. For any $S$, the three postplayroom blood samples were taken no more than $.5,1.5$, and $2.5 \mathrm{~h}$ after the end of the playroom test. The order in which blood samples were taken from the animals was determined randomly, with the same order used for all samples on that day. A second playroom test was conducted 2 days later, using the identical procedures.

\section{Behavioral Data}

The behavioral scoring system included six mutually exclusive categories, exhaustive of all observed responses. These included (i) positive social (play, all nonaggressive social interactions involving mutual clinging, grooming, and nonspecific contact), (ii) social look (head and body oriented toward another monkey), (iii) fear-disturbance (fear grimacing, spatial withdrawal from contact, screeching, self-clutching, repetitive rocking, stereotyped responses while in a stationary, huddled posture), (iv) visual explore (head and eye orientation or scanning of any specific part of the inanimate environment), (v) physical explore (manual and/or oral manipulation of the inanimate environment, and (vi) threat (aggressive posturing, facial expressions, and/or vocalization directed toward monkeys or specific parts of the inanimate environment). The two experienced Os had recently generated reliability coefficients of $r>+.90$ on these categories.

\section{Statistical Analy'sis}

Overall and interaction effects were evaluated by repeated measure ANOVAs. Where interactions were significant, group differences in simple effects were assessed by randomization tests to preserve maximal power with the small samples studied.

\section{RESULTS AND DISCUSSION}

\section{ACTH Injection}

The ACTH test (Fig. 1, Panel 1) revealed isolate basal cortisol levels $(\overline{\mathrm{X}}=41.1 \mu \mathrm{g} / 100 \mathrm{ml}$ plasma) almost twice as high as those for peer Ss $(\bar{X}=24.0)(p=.014$ by randomization test). Absolute cortisol was highest at Hours 2 and 3 , followed by a decrease at Hour $4(\mathrm{~F}=$ 24.65 , df $=3 / 18, p<.001$ for hours main effect). Although the mean isolate cortisol values were slightly higher than peer $S$ values at Hours 1.4 after injection, neither the group main effect $(F=2.01$, df $=1 / 6$, $\mathrm{p}>.25)$ nor the Group by Hour interaction $(\mathrm{F}=1.73$, $\mathrm{df}=3 / 18, \mathrm{p}>.25)$ were significant. Thus, isolate adrenals were more active under nonstimulated home cage conditions, but both groups could be stimulated by ACTH to much higher, equivalent, absolute cortisol levels.

\section{Playroom Tests}

On Playroom Test 1 (Fig. 1, Panel 2), isolates again had higher basal cortisol $(\overline{\mathrm{X}}=42.8 \mu \mathrm{g} \%)$ than their peers $(\overline{\mathrm{X}}=24.1 \mu \mathrm{g} \%)(\mathrm{p}=.014$ by randomization test $)$. Immediately after this test, isolates had a nonsignificant rise in cortisol $(\overline{\mathrm{X}}=3.5 \mu \mathrm{g} \%, \mathrm{p}>.50$ by randomization test), whereas peers had a larger increase $(\bar{X}=11.2 \mu \mathrm{g} \%$, $p=.062$, the most significant $p$ value possible for correlated scores when $N=4$ ). At Hours 3 and 4 , the isolates were below basal levels, whereas peers did not return to basal level by Hour 4 . Thus, the initial encounter with the playroom environment produced a slight adrenal response in peer-raised monkeys, but failed to produce the expected large reaction in isolation-raised animals.

On Playroom Test 2 (Fig. 1, Panel 3) isolates $(\overline{\mathrm{X}}=$ $36.9 \mu \mathrm{g} \%)$ again had higher basal cortisol than did peers $(\overline{\mathrm{X}}=26.6 \mu \mathrm{g} \%)(\mathrm{p}=.041$ by randomization test $)$. Isolate cortisol did increase immediately after playroom testing $(\overline{\mathrm{X}}$ increase $=23.5 \mu \mathrm{g} \%, \mathrm{p}=.062$, the maximum randomization test value), and peers also showed elevated cortisol at Hour $2(\overline{\mathrm{X}}$ increase $=14.9 \mu \mathrm{g} \%, \mathrm{p}=$ .062). However, the difference between groups in increase from basal levels was not significant $(p=.257$ 
by randomization test). Both groups returned to basal levels by Hour 3. These data indicate some adrenal effect of Playroom Test 2 on both groups, even though the situation was no longer novel.

\section{Playroom Behavior}

Behaviors on both playroom tests were summarized (Fig. 2) by mean percent of the 10-min test time spent in each of the six response categories. Peers spent most of their time interacting, sitting together, looking at other monkeys, or exploring the environment. Although they did look at other monkeys, isolates spent little time physically contacting them. The largest portion of isolate behavior involved fear, self-clutching, and rock-huddle withdrawal behavior. The profiles were the same on both playroom tests, indicated by no significant days or Group by Days interaction effects on any of the six categories (all $\mathrm{p}>.25$ ). Thus, the fear-withdrawal self-directed behavior syndrome seen when isolates are introduced to novel environments was characteristic of our isolate Ss.

Two findings concerning the adrenal response of these socially and isolate raised monkeys appear to be clear. First, isolates had much higher basal levels of plasma cortisol. This effect suggests that isolate monkeys are under more chronic physiological "stress" when unstimulated, if absolute cortisol level can be interpreted as a chronic stress measure. Second, isolates did not have more reactive adrenal systems on the ACTH test, and isolates did not show a higher cortisol response following the environmental stress of a novel, complex situation. If anything, the peer-raised Ss were more physiologically reactive to the playroom than were the isolates.

Adrenocortical output under conditions of novel and complex stimulation has been interpreted as a measure of stress, arousal, or emotionality (e.g., Denenberg, 1967). The isolate behavior syndrome of atypical motor activity, fear, and withdrawal, has also been related to heightened arousal or emotional reactions to intense, novel, or complex input (e.g., Fuller, 1967). The failure of our isolates to show cortisol increases on the first playroom test is contrary to the interpretation of induced cortisol level as a measure of emotional or "stress" response. Also, the finding of elevated isolate cortisol response on the second playroom test, with no concomitant change in isolate behavior, argues against a "stress" or emotionality interpretation of absolute cortisol-level measures. Thus, these results suggest that either isolate monkeys are not hyperemotional or absolute level of adrenal output stimulated by novel and complex input is unrelated to arousal or emotionality. Similar results, contradictory to an emotional response interpretation of cortisol changes, were reported by Meyer and Bowman (1972), who found no differential cortisol reactions to chair restraint stress between isolate and socially reared 4-year-old rhesus monkeys. This lack of relationship between adrenal steroid level and

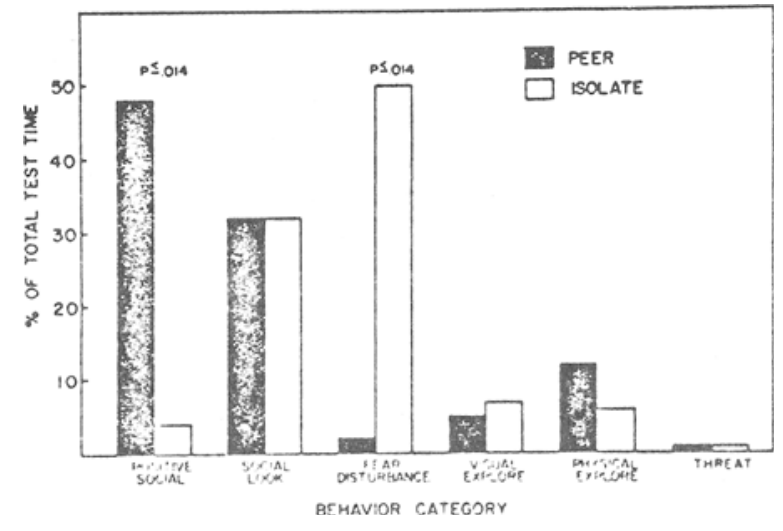

Fig. 2. Behavioral profiles showing percentage of the $10 \mathrm{~min}$ test time spent in each type of response, averaged over the two playroom tests.

behavioral emotionality is also consistent with work by Ader (1969), who correlated several rodent behaviors under stress conditions with corticosterone and found little association between steroid change and indices of behavioral emotionality.

\section{Evidence for "True" Basal Level Measurement}

One question concerning these data is whether basal differences reflected "true" unstimulated cortisol effects or whether the procedures employed in capture and blood drawing were responsible for group differences. Bowman and Wolf (1969) studied cortisol level induced by ACTH in similar aged, laboratory raised, rhesus monkeys. They found a $.3-\mu \mathrm{g} \% / \mathrm{min}$ rise in cortisol during the first hour after basal blood drawing. The rate of ACTH-induced cortisol rise during Hour 1 of our study was comparable at $.5 \mu \mathrm{g} \% / \mathrm{min}$. These data lead to a predicted rise of $6-10 \mu \mathrm{g} \%$ in $20 \mathrm{~min}$, if the Ss of this study were maximally stressed by our blood-drawing procedures. Capture and blood drawing took no more than 4 min each for our Ss, yet we observed a basal-level difference which was $20 \mu \mathrm{g} \%$ higher in isolates than in peers, and the rate of rise in cortisol during Hour 1 did not differ appreciably between groups. Thus, even maximal blood-drawing stress on isolates coupled with no blood-drawing stress on peers could not have accounted for the basal differences.

\section{REFERENCES}

Ader, R. Adrenocortical function and the measurement of "emotionality." Annals of the New York Academy of Sciences, 1969, 159, 791-805.

Bowman, R. E., \& DeLuna, R. F. Assessment of protein-binding method for cortisol determination. Annals of Biochemistry, 1968, 26, 465-469.

Bowman, R. E., \& Wolf, R. C. Plasma 17-hydroxycorticosteroid response to ACTH in $M$. mulatta: Dose, age, weight, and sex. Proceedings of the Society of Experimental Biology \& Medicine, 1969, 130, 61-64.

Denenberg, V. H. Stimulation in infancy, emotional reactivity 
and exploratory behavior. In D. C. Glass (Ed.), Neurophysiology and emotion. New York: Rockefeller University Press, 1967. Pp. 161-190.

Fox, M. W. Socialization, environmental factors, and abnormal behavioral development in animals. In M. W. Fox (Ed.), Abnormal behavior in animals. Philadelphia: Saunders, 1968.

Fuller, J. L. Experiential deprivation and later behavior. Science, $1967,158,1645-1652$.

Harlow, H. F., Dodsworth, R. O., \& Harlow, M. K. Total social isolation in monkeys. Proceedings of the National Academy of Sciences, 1965, 54, 90-97.

Hess, J. L., Denenberg, V. H., Zarrow, M. X., \& Pfeifer, W. D. Modification of the corticosterone response curve as a function of handling in infancy. Physiology \& Behavior, 1969, 4, 109-111.

Levine, S. Psychophysiological effects of infantile stimulation. In E. L. Bliss (Ed.), Roots of behavior. New York: Hoeber, 1962. Pp. 246-253.

Levine, S., Haltmeyer, G. C., Karas, G. C., \& Denenberg, V. H. Physiological and behavioral effects of infantile stimulation. Physiology \& Behavior, 1967, 2, 55-59.

Mason, J. W. A review of psychoendocrine research on the pituitary-adrenal cortical system. Psychosomatic Medicine, $1968,30,576-585$.

Melzack, R., \& Scott, T. H. The effect of early experience on response to pain. Journal of Comparative \& Physiological Psychology, 1957, 50, 155-161.

Meyer, J. S., \& Bowman, R. E. Rearing experiences, stress, and adrenocorticosteroids in the rhesus monkey. Physiology \& Behavior, 1972, 8, 339-344.

Sackett, G. P. Abnormal behavior in laboratory-reared rhesus monkeys. In M. W. Fox (Ed.), Abnormal behavior in animals. Philadelphia: Saunders, 1968. Pp. 293-331.

Sackett, G. P. Innate mechanisms, rearing conditions, and a theory of early experience effects in primates. In M. R. Jones (Ed.), Miami symposium on prediction of behavior: Early experience. Miami: University of Miami Press, 1970. Chap. 1.

Scott, J. P. Critical periods in behavioral development. Science, 1962, 138, 949-958.

(Received for publication February 1, 1973; accepted March 19, 1973.) 